\title{
Sialidosis type 1
}

INSERM

\section{Source}

INSERM. (1999). Orphanet: an online rare disease and orphan drug data base. Sialidosis type 1. ORPHA:812

Sialidosis type 1 (ST - 1 ) is a very rare lysosomal storage disease, and is the normosomatic form of sialidosis (see this term), characterized by gait abnormalities, progressive visual loss, bilateral macular cherry red spots and myoclonic epilepsy and ataxia, that usually presents in the second to third decade of life. 